\title{
Increased extracellular volume and altered mechanics are associated with left ventricular hypertrophy in hypertensive heart disease, not hypertension alone
}

\author{
Sujith Kuruvilla ${ }^{1 *}$, Rajesh Janardhanan ${ }^{1}$, Yang Yang ${ }^{3}$, Yasmin S Hamirani ${ }^{1}$, Frederick H Epstein ${ }^{3}$, Ellen C Keeley ${ }^{1}$, \\ Christopher M Kramer ${ }^{1,2}$, Michael Salerno ${ }^{1,3}$
}

From 17th Annual SCMR Scientific Sessions

New Orleans, LA, USA. 16-19 January 2014

\section{Background \\ Study purpose}

To detect differences in extracellular volume (ECV) and systolic strain in hypertensive patients with LVH as compared to hypertensive patients without LVH and age-matched controls. Background: Increased ECV due to diffuse myocardial fibrosis in hypertensive patients may be an underlying mechanism contributing to increased cardiovascular risk. Moreover HTN patients with left ventricular hypertrophy (LVH) are at higher risk of cardiovascular morbidity and mortality when compared to HTN Non-LVH subjects. We compared levels of ECV and systolic strain between HTN LVH, HTN Non-LVH and control subjects.

\section{Methods}

T1 mapping was performed in $21 \mathrm{HTN}$ LVH $(55 \pm$ 11 years), 12 HTN Non-LVH (60 \pm 14 years) and 21 control $(52 \pm 9)$ subjects on a Siemens $1.5 \mathrm{~T}$ Avanto using 3-5 MOLLI (11 heart beats, 2 inversions, 3 recovery beats, 8 images). Patients with known coronary disease, significant valvular disease, and other causes of LVH were excluded. MOLLI sequence parameters included: echo time/repetition time/flip angle $1.1 \mathrm{~ms} / 2.5$ $\mathrm{ms} / 35^{\circ}$, field of view $340 \times 260$, resolution $1.8 \mathrm{~mm} \times 1.8$ $\mathrm{mm}$, thickness $8 \mathrm{~mm}$. T1 was determined pre-contrast and 10,15 and 20 minutes following injection of 0.15 $\mathrm{mmol} / \mathrm{kg}$ Gd-DTPA. T1 maps were generated using an

${ }^{1}$ Cardiology, University of Virginia Medical Center, Charlottesville, Virginia, USA

Full list of author information is available at the end of the article in-house MATLAB program. Partition Coefficient $(\lambda)$ was determined from the slope of a plot of $1 / \mathrm{T} 1$ of the myocardium versus $1 / \mathrm{T} 1$ of the blood. Volume of distribution (Vd) was calculated as $\lambda *$ (1-Hematocrit). LV mass and function was assessed by SSFP cine imaging. Circumferential strain measurements were performed using cine DENSE. Values were compared between groups using one-way ANOVA.

\section{Results}

HTN LVH subjects had significantly higher BP, LV mass and were on more anti-hypertensive medications when compared to HTN Non-LVH subjects and controls (Table 1). HTN LVH subjects had higher levels of ECV, as measured by $\lambda$ and $\mathrm{Vd}$, when compared to HTN Non-LVH and control subjects (Table 1 and Figure 1). Peak mid-wall circumferential strain was significantly reduced in HTN LVH subjects as compared to HTN Non-LVH subjects and controls $(-0.12 \pm 0.02$ vs. $-0.16 \pm$ $0.03, \mathrm{p}=0.006$ and $-0.17 \pm 0.03, \mathrm{p}<0.001$, respectively).

\section{Conclusions}

HTN LVH patients had higher ECV and associated reduction in mid-wall circumferential strain when compared to HTN Non-LVH and control subjects. Increased ECV as a surrogate for diffuse fibrosis in HTN LVH subjects may explain the increased cardiovascular morbidity and mortality seen in HTN LVH as compared to other HTN subtypes.

\section{Funding}

AHA 10SDG2650038. 


\section{Table 1}

\begin{tabular}{cccc}
\hline & Age-matched controls $(\mathbf{n}=\mathbf{2 1})$ & Hypertensive Non-LVH $(\mathbf{n}=\mathbf{1 2})$ & Hypertensive LVH $(\mathbf{n}=\mathbf{2 1})$ \\
\hline Sex & 15 females; 6 males & 6 females; 6 males & 13 females; 8 males \\
\hline Age (yrs) & $52 \pm 9$ & $60 \pm 14$ & $55 \pm 11$ \\
\hline Systolic BP $(\mathrm{mm} \mathrm{Hg})$ & $120 \pm 16$ & $136 \pm 13 \wedge$ & $156 \pm 21^{* \wedge}$ \\
\hline Diastolic BP (mm Hg) & $69 \pm 10$ & $77 \pm 12$ & $88 \pm 14 \wedge$ \\
\hline Heart Rate & $72 \pm 12$ & $72 \pm 12$ & $73 \pm 16$ \\
\hline Number of HTN meds & 0 & $2.0 \pm 1.3 \wedge$ & $3.0 \pm 1.5 \wedge$ \\
\hline LV Mass (g) & $75 \pm 20$ & $85 \pm 23$ & $147 \pm 40^{* \wedge}$ \\
\hline LVMl & $41 \pm 8$ & $41 \pm 9$ & $71 \pm 16^{* \wedge}$ \\
\hline Partition Coefficient & $0.43 \pm 0.02$ & $0.45 \pm 0.02$ & $0.48 \pm 0.04^{* \wedge}$ \\
\hline Volume of Distribution & $0.26 \pm 0.02$ & $0.26 \pm 0.02$ & $0.28 \pm 0.02^{* \wedge}$ \\
\hline Mid-CircumferentialStrain & $-0.17 \pm 0.03$ & $-0.16 \pm 0.03$ & $-0.12 \pm 0.02^{* \wedge}$ \\
\hline
\end{tabular}

${ }^{*}=\mathrm{p}<0.05$ vs. Non-LVH groups. $\wedge=p<0.05$ vs. controls. $]$

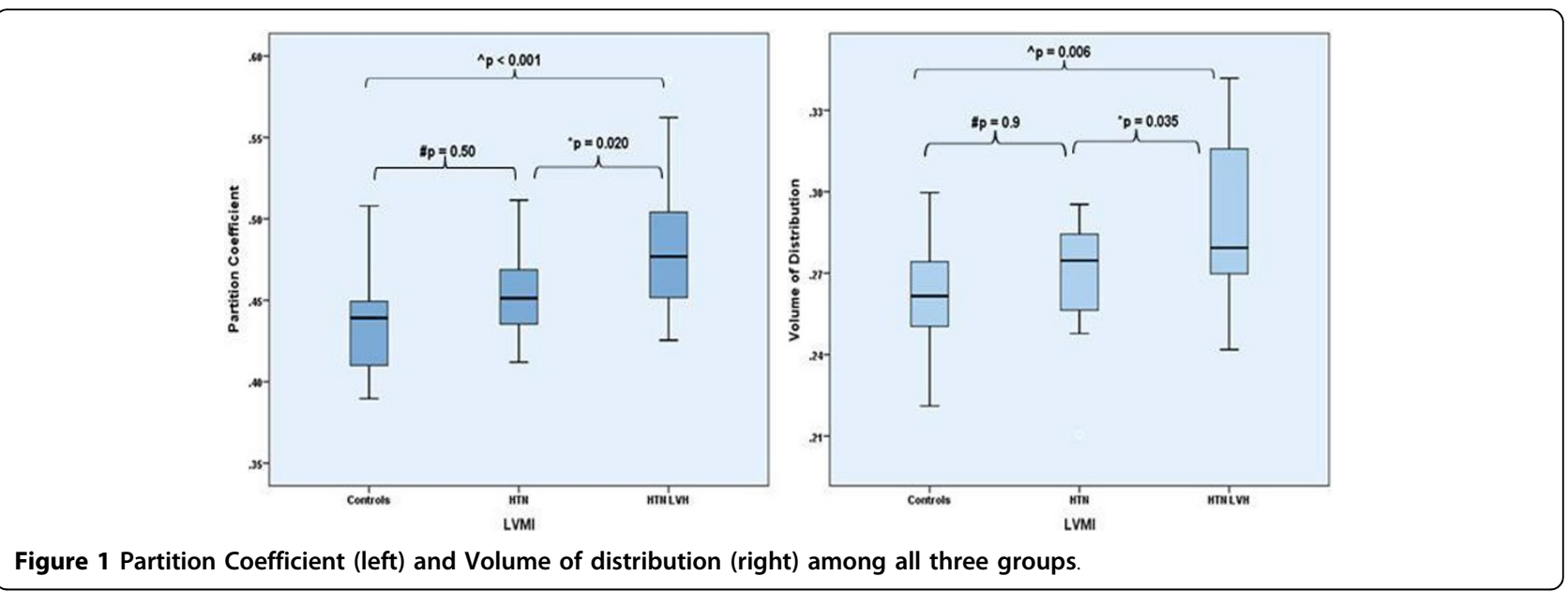

\section{Authors' details}

${ }^{1}$ Cardiology, University of Virginia Medical Center, Charlottesville, Virginia,

USA. ${ }^{2}$ Radiology, University of Virginia Health System, Charlottesville, Virginia,

USA. ${ }^{3}$ Biomedical Engineering, University of Virginia Health System,

Charlottesville, Virginia, USA.

Published: 16 January 2014

doi:10.1186/1532-429X-16-S1-P393

Cite this article as: Kuruvilla et al:: Increased extracellular volume and altered mechanics are associated with left ventricular hypertrophy in hypertensive heart disease, not hypertension alone. Journal of

Cardiovascular Magnetic Resonance 2014 16(Suppl 1):P393.

\section{Submit your next manuscript to BioMed Central} and take full advantage of:

- Convenient online submission

- Thorough peer review

- No space constraints or color figure charges

- Immediate publication on acceptance

- Inclusion in PubMed, CAS, Scopus and Google Scholar

- Research which is freely available for redistribution

Submit your manuscript at www.biomedcentral.com/submit 